\title{
Catenary Voltage Supply: Locomotive by using Active Line Side Converter
}

\author{
K. Gugan*, S. V. Saravanan and D. Dafny Lydia \\ Department of Electrical and Electronics Engineering, AMET University, Chennai - 603112, Tamil Nadu, \\ India; kgugan@ymail.com
}

\begin{abstract}
In traction networks, voltage drop in catenary line is a general problem being faced. By injection of capacitive reactive power to the current controlled active line-side converter losses can be reduced in locomotives. Then catenary voltage is compared with the reference value and the error is fed to PI controller. The controller generates a reference value of converter current which will lead to reactive power injection. The catenary parameters are identified by harmonic current injection. The performance of the proposed control strategy is evaluated in MATLAB- Simulink. The proposed method is applied to reduce the voltage drop in catenary line of locomotive and the optioned result are compared with those of the conventional method.
\end{abstract}

Keywords: Building Integrated Photovoltaics, Li-Fi, V2V Communication, Visible Light Communication

\section{Introduction}

AC Traction systems are provided by weak single-phase grids connections, where lot of distortions occur in the system. The old locomotives are still in existence which is carried with passive line-side converter. Locomotive have distortion in the voltage and current due to weak network which affect the physical connection to the traction systems. The line-side converter of locomotive is the main reason for the effects on the network voltage and current. This determines how the traction system are affected by the voltage distortions ${ }^{1}$. Traditionally, two major kind of passive line side converters have been being employed 1) Diode rectifier 2) Phase-angle controlled thyristor converters. These topologies distorted current with low harmonic distortions and consequently pollute the network voltage. Which result in several power degradation harmonic overvoltages. The excitation of the resonance modes of the transmission line occur due to the harmonic overvoltage. The excited voltage is added to the voltage, it result in the overvoltage than the rated voltage. Moreover. the use of diode rectifier can result in the loss of aver- age voltage. This is due to rectifier commutations, leads to significant notching in the voltage lead to average rectified voltage. Low system voltage normally happen at the end of heavy loaded line. This is supplied by substation or in the middle of the line connected between two substations. The effect of the low system voltage is maximum. Low system voltages limit the

Performance of the locomotives and limit the maximum transmittable power along the line. The advancement of the semiconductor help to commutate high relative frequency using high voltage and current IGBT switches, e.g., $1-2 \mathrm{KHz}$, can be utilized to tom a PWM four quadrant line-side converter. The reduction of switching harmonics at the catenary can be achieved by adopting converters at switching frequency higher than $1 \mathrm{Khz}$. Practically no low-order harmonic current is generated. Therefore a modern locomotive does not have the passive line-side converter. The old SCR/diode -based locomotives are replaced by PWM based compensators which elevate the importance of lower order harmonic related issues. The most common issue found in both old and new locomotives is low voltage system. Increase in

${ }^{*}$ Author for correspondence 
the speed and power of locomotive is have marked the importance of low voltage system. Thyristor-switched reactors and thyristor-switched capacitor have been used in the existing system to overcome the low voltage system. But several semiconductor based system are proposed and even super capacitor based compensator are suggested. But all this system are static and locally compensate the problem. But in few cases cost plays a major role for the implementation of the system.

To overcome the disadvantages over the passive lineside converter (low system voltage) an active line side converter had been supported on the recent locomotive to overcome the curve voltage. The static compensator (STATCOM) is used as active line-side converter to support the network with capacitive reactive power to compensate the voltage drop on the line. The disturbance between the amplitude of the curve voltage and it rated value is fed to PI controller. The output of the controller is that the q-axis of this, that states the specified reactive power. The locomotive position is not fixed, once PI controller isn't unable to stabilize the system to produce acceptable performance to all position. The characteristics the parameter. Again-scheduled controller is used. These parameters are referred with catenary parameters .within the following once that low-system voltage is identified is characterized with catenary parameters, the voltage compensator will be elaborated.

\section{System Description}

The schematic diagram of the system represent an AC single phase traction network with a locomotive connected by a catenary through a mechanical devices. Two substation form's the catenary line which is sixty $\mathrm{km}$ away from each substation. The catenary line is installed with resistance and inductance, the locomotive is connected to the catenary through coupling transformer, that is modelled with a transformer and its leak inductance along with series resistance are portrayed by and respectively.

The active line-side converter of the locomotive drive system is enforced by a full-bridge single-phase IGBTbased inverter ${ }^{2}$. Note that the $\mathrm{dc}$ link of the inverter consists of a capacitor bank whose voltage is regulated at $900 \mathrm{~V}$. Moreover, note that the dynamics of the locomotive motor and its driver are neglected, and a rheostat represents the important power demand of the locomotive. Summarizes the parameters of the system. Note that the line impedance is divided into 2 parts consistent with the position of the locomotive. The segmentation within which every portion is portrayed by a variable impedance, i.e., and. Moreover, note that there's no line reactor filter value-added to harmonic shift filtering. The rationale is that the leak inductance of the adopted transformer is massive enough and is exploited to the shift harmonic filtering.

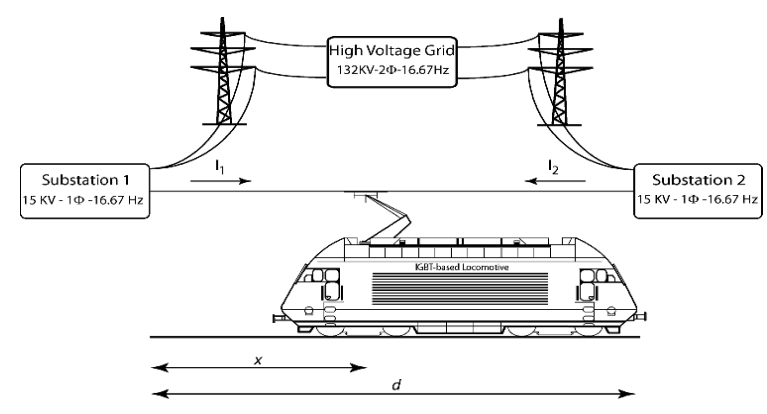

Figure 2.1. Schematic diagram of locomotive.

However, constant analysis will be performed to a traction system consisting of only one station. One will assume that the locomotive of Figure. One is intense watts of real power and is found kilometres far from station one, i.e., SS1. The length of the line is kilometres. Applying KVL to the system, the following is deduced:

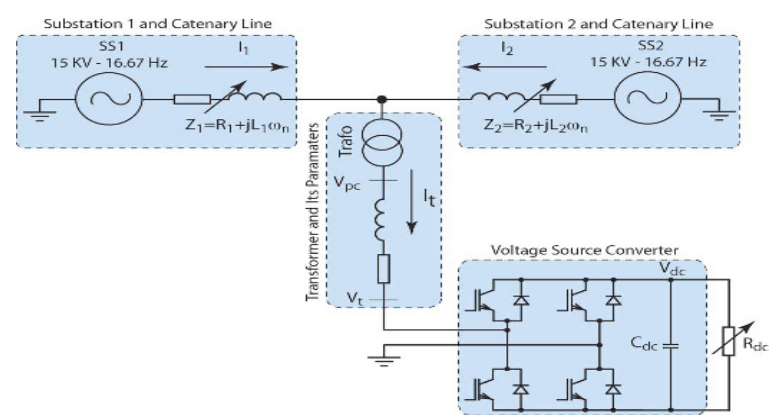

Figure 2.2. Representation on voltage control in traction system.

$\mathrm{Vss}_{1}=\mathrm{nVpc}+\mathrm{Z1I} 1$

in which is the turn ratio of the transformer

$\mathrm{Z}_{\mathrm{n}}=\mathrm{R}_{1}+\mathrm{jW}_{\mathrm{n}} \mathrm{L}_{1}$

Adopting the diagram, one can deduce

$\mathrm{V}^{2}{ }_{\mathrm{ss}}=\left(\mathrm{n} \mathrm{V} \mathrm{pc}+\mathrm{R}_{1} \mathrm{I}_{1}\right)^{2}+\left(\mathrm{Wn} \mathrm{L1} \mathrm{I}_{1}\right)^{2}$

Assuming the impedance of the line per kilometer is

$\mathrm{Z}_{\mathrm{L}}=\mathrm{R}_{\mathrm{L}}+\mathrm{j} \mathrm{W}_{\mathrm{n}} \mathrm{L}_{\mathrm{L}}$ andVss $=\mathrm{Vss}_{2}$

the current of SS1, i.e., is expressed in terms of the locomotive current as follows: 


$$
\mathrm{NI}_{1}=\mathrm{Z}_{2} / \mathrm{Z}_{1}+\mathrm{Z}_{2} \mathrm{IT}=(\mathrm{D}-\mathrm{X}) \mathrm{Z}_{\mathrm{L}} / \mathrm{DZ} \mathrm{L}_{\mathrm{T}}
$$

Moreover, the locomotive current is expressed in terms of its real power consumption and the catenary voltage as:

$$
\mathrm{I}_{\mathrm{T}}=\mathrm{P} / \mathrm{V}_{\mathrm{PC}}
$$

Substituting to $\mathrm{I}_{\mathrm{t}}$ from (4) in (3), the following is deduced

$$
\mathrm{I}_{1}=(1-\mathrm{x} / \mathrm{d}) \mathrm{P} / \mathrm{nVpc}
$$

Moreover, substituting to from (5) in (2), the following is derived:

$$
\begin{aligned}
& \mathrm{n}(\mathrm{Vpc})^{4}+\left(2 \mathrm{R}_{1} \mathrm{P}(1-\mathrm{x} / \mathrm{d})-\mathrm{V}^{2} \mathrm{ss}_{1}\right)(\mathrm{nVp})^{2}+\left(\mathrm{R}_{1}^{2}+\left(\mathrm{L}_{1 \mathrm{n}}\right)\right. \\
& \mathrm{P}(1-\mathrm{x} / \mathrm{d})=0
\end{aligned}
$$

Substituting $\mathrm{xR}_{1}$ and $\mathrm{xL}_{1}$ to $\mathrm{R}_{1}$ and $\mathrm{L}_{1}$, respectively, in (6), the following is achieved.

$$
\begin{aligned}
& \mathrm{n}(\mathrm{Vpc})^{4}+\left(2 \mathrm{R}_{1} \mathrm{P}(1-\mathrm{x} / \mathrm{d})-\mathrm{V}^{2} \mathrm{ss}_{1}\right)(\mathrm{nVp})^{2}+\left(\mathrm{R}_{1}^{2}+\left(\mathrm{L}_{1 \mathrm{n}}\right)\right. \\
& \mathrm{P}(\mathrm{x}-\mathrm{x} / \mathrm{d})=0
\end{aligned}
$$

The voltage of the catenary at the connection point of the locomotive to the network is then determined. The voltage of the catenary as a function of the locomotive physical position, to several power demand levels. Absorbing real power from the catenary results in the voltage drop along the line.

\section{Low System Voltage Compensation}

Having lower voltage within the middle of the line not solely limits the performance of the locomotives fed by the affected line, however additionally it limits the capability of the road. That is, less real power are often transmitted through the affected line. However, injecting reactive power through the active line-side converter of the locomotive, one will compensate to the voltage drop on the road while not installing new infrastructure ${ }^{3,4}$. Forward the phase-angle between the locomotive voltage and current is, the phases comparable to the locomotive voltage, SS1 voltage, and also the current flowing from SS1 to the locomotive area unit as represented in Taking identical procedure as explained to scheming the locomotive voltage operating with one will verify the voltage of the locomotive that operates at the ability issue. Operational at capacitive power factors, the injected reactive power. Catenary voltage on the line versus the space of a $9 \mathrm{MW}$ locomotive from SS1 to 3 different reactive powers, the drop on the line is remunerated levels of compensation.
Line-side converter capability compensates to the voltage drop on the line caused by real power demand of the locomotive ${ }^{2}$. Forward a true power demand of nine MW the voltage profile across the line or 3 totally different levels of reactive power injection, i.e., 3 totally different power factors verifies that injecting capacitive.

\section{Line-Side Converter Control Strategy}

The common observe to the active line-side converter of locomotives is utilizing current management schemes to the regulation of the input current, that itself leads to the active and reactive power regulation. The traditional approaches to this regulation of single-phase converters are rotating reference system (RRF) controllers, e.g., PI-based approaches and stationary reference system (SRF) controllers, e.g., proportional-resonant (PR)-based ways, PR-based current management scheme is adopted to this regulation. To the synchronization functions and reference current generation, a second-order generalized measuring device (SOGI) single-phase phase locked loop (PLL) is adopted. SOGI PLL generates an orthogonal element of the pc voltage and acts on the pc voltage and its orthogonal part to extract the phase-angle. In the following, 1st PR-controller is in brief explained, and then, the generation of the reference signal is discussed ${ }^{15}$. Finally the voltage support scheme, that generates the desired $\mathrm{q}$-axis reference current.

\section{Proposed System}

The figures shows the block diagram arrangement of proposed system of the converter circuit.

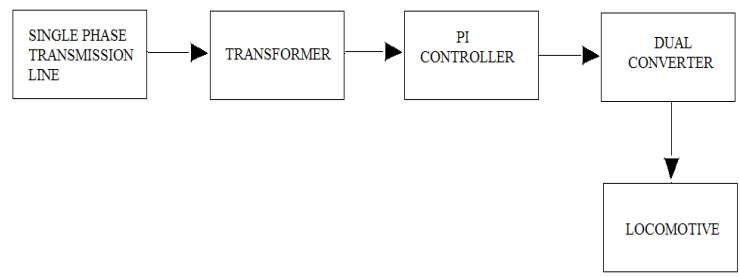

Figure 3.1. Block Diagram of proposed System.

\section{Operation of Proposed System}

A voltage support scheme to traction networks, that compensates to the drop on the catenary line to that locomotives are connected. Within the projected technique capacitive reactive power is injected to the current controller active line side converter in locomotive. Compression between catenary voltage are reference value, error are fed to gain scheduled PI controller. Q-axis reference value of 
converter current is accountable to reactive power injection. The parameters of catenary line are known using gain programing.

\section{Output Waveform}

The voltage drop in the catenary line can be compensated by active line side converter; the active line side converter in the locomotive will is injected by the capacitive reactive power. The simulation has developed in the matlab-simulink for the system. And the output has been potted for voltage and current. It show the drop had been overcome by the developing active line-side converter.

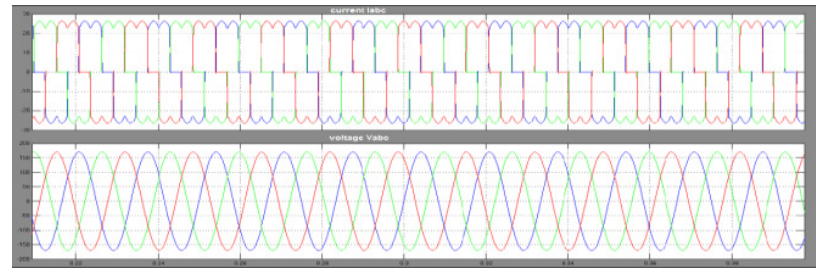

The current raise and fall with a predetermined steepness to resemble the acceleration and deceleration.

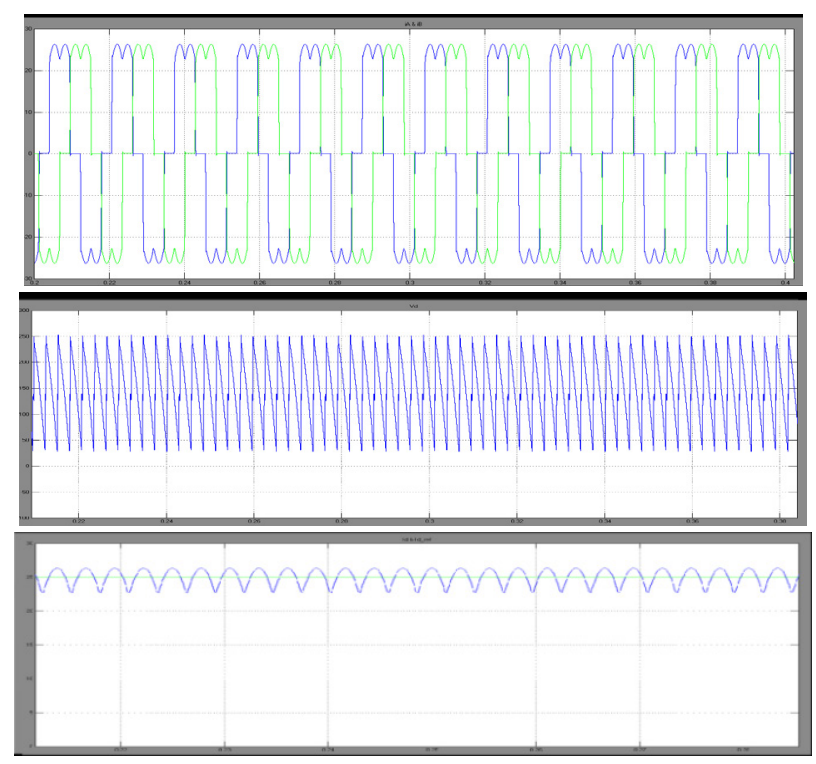

The output reference current of $\mathrm{dc}$ motor as been become stable by using active line side converter.

\section{Conclution}

The projected methodology compensate to the drop on the catenary line caused by real power absorption of the locomotives using a gain-scheduled PI-controller fed by the voltage error, the compensation scheme injects capacitive reactive power through the current-controlled active line-side converter of locomotives. The gain-scheduling to the PI-controller is performed through the identification of the line parameters. Moreover, the identification is meted out by the injection of harmonic frequency current. It show the drop had been overcome by the developing active line-side converter.

\section{Reference}

1. Busco B, Marino P, Porzio M, Schiavo R and Vasca F. Digital control and simulation to power electronic apparatus in dual voltage railway locomotive. IEEE Transactions on Power Electronics. 2003 Sep; 18(5):1146-57. Crossref.

2. Chang GW, Hsin-Wei L and Shin-Kuan C. Modeling characteristics of harmonic currents generated by high-speed railway traction drive converters. IEEE Transactions on Power Delivery. 2004 Apr; 19(2):766-73. Crossref.

3. Chen SL, Li RJ and Pao-Hsiang H. Traction system unbalance problem-analysis methodologies. IEEE Transactions on Power Delivery. 2004 Oct; 19(4):1877-83. Crossref.

4. Hung-Yuan $\mathrm{K}$ and Tsai-Hsiang C. Rigorous evaluation of the voltage unbalance due to high-speed railway demands. IEEE Transactions on Vehicular Technology. 1998 Nov; 47(4):1385-9. Crossref.

5. Sy-Ruen H and Bing-Nan C. Harmonic study of the le blanc transformer to Taiwan railway's electrification system. IEEE Transactions on Power Delivery. 2002 Apr; 17(2):495-9. Crossref.

6. Cheng-Ping H, Chi-Jui W, Yung-Sung C, Shih-Kai P, JungLiang $\mathrm{Y}$ and Ming-Hong $\mathrm{H}$. Loading characteristics analysis of specially connected transformers using various power factor definitions. IEEE Transactions on Power Delivery. 2006 Jul; 21(3):1406-13.

7. Otto RA, Putman TH and Gyugyi L. Principles and applications of static, thyristor-controlled shunt compensators. IEEE Transactions on Power Apparatus and Systems. 1978 Sep; PAS-97(5):1935-45. Crossref.

8. Li X and Zuo L. Research on balance compensation of statcom. Proceedings of 2 nd IEEE Conference on Industrial Electronics and Applications. 2007; p. 563-8.

9. Senini $S$ and Wolfs PJ. Hybrid active filter to harmonically unbalanced three phase three wire railway traction loads. IEEE Transactions on Power Electronics. 2000 Jul; 15(4):702-10. Crossref.

10. Cecati C, DellAquila A and Monopoli VG. Design of h-bridge multi level active rectifier to traction systems. IEEE Transactions on Industry Applications. 2003 Sep/Oct; 39(5):1541-50. Crossref.

11. Fujita H. A single-phase active filter using an h-bridge PWM converter with a sampling frequency quadruple of the switching frequency. IEEE Transactions on Power Electronics. 2008 Apr; 24(4):934-41. Crossref. 
12. Tanaka T, Hiraki E, Ueda K, Sato K and Fukuma S. A novel detection method of active and reactive currents in singlephase circuits using the correlation and cross-correlation coefficients and its applications. IEEE Transactions on Power Delivery. 2007 Oct; 22(4):2450-6. Crossref.

13. Sung-Yeul $P$, Chien-Liang $C$ and Lai JSJ. A wide-range active and reactive power flow controller to a solid oxide fuel cell power conditioning system. IEEE Transactions on Power Electronics. 2008 Nov; 23(6):2703-9. Crossref.
14. Nishida K, Rukonuzzman M and Nakaoka M. Advanced current control implementation with robust deadbeat algorithm to shunt single-phase voltage-source type active power filter. IEE Proceedings - Electric Power Applications. 2004 May; 151(3):283-8. Crossref.

15. Kunjumuhammed LP and Mishra MK. A control algorithm to single phase active power filter under non-stiff voltage source. IEEE Transactions on Power Electronics. 2006 May; 21(3):822-5. Crossref. 